\title{
BACTERIAL COMMUNITY STRUCTURE AND DIVERSITY IN THE SOIL OF THREE DIFFERENT LAND USE TYPES IN A COASTAL WETLAND
}

\author{
Geng, X. D. ${ }^{1}-$ ZhOU, Y. ${ }^{1}-$ WANG, C. Z. ${ }^{1}-$ YU, M. H. ${ }^{2}$ - QIAN, J. L. ${ }^{1 *}$ \\ ${ }^{1}$ Suzhou Polytechnic Institute of Agticulture, Suzhou 215008, PR China \\ ${ }^{2}$ Suzhou Horticultural Station, Suzhou 215128, PR China \\ *Corresponding author \\ e-mail:qianjl03@126.com
}

(Received $8^{\text {th }}$ Jul 2020; accepted $7^{\text {th }}$ Oct 2020)

\begin{abstract}
The effect of land use on soil bacterial community structure and diversity was studied in three typical land use types in the Yancheng National Nature Reserve, China. These represented long-term arable land use, pristine wetland, and long-term forest land. Physico-chemical parameters of the soils were determined, and high-throughput sequencing of V3 fragments of the bacterial 16S rRNA amplicons was applied to study the community structure of soil bacteria and explore relationships with soil properties. The results showed that in all three soil types the dominant bacterial phyla were Acidobacteria, Proteobacteria, and Actinobacteria, whose abundance differed with land use patterns. Combined with Chao index and ACE index, we found that the bacterial richness of arable land was significantly higher than that of forest or wetland soil. The Simpson and Shannon indices were similar in the three soils, indicating that there was no significant difference in bacterial community diversity. Acidobacteria were most abundant in wetland soil, forest soil was rich in Actinobacteria, and arable soil contained Proteobacteria and Firmicute at high abundance. Correlation analysis identified that soil acidity and moisture content were important driving factors affecting the microbial community composition and structure.
\end{abstract}

Keywords: land reclamation, high-throughput sequencing, bacterial community, soil pH, diversity, wetlands

\section{Introduction}

Different land use patterns cause changes in the terrestrial ecology and in the local biogeochemical cycles, leading to changes in soil properties and land productivity (Sun et al., 2015). Changes in land use patterns can fundamentally change the soil quality and cycling of nutrients (in particular $\mathrm{C}, \mathrm{N}$, and $\mathrm{P}$ ) that affect the soil microbial communities, for arable land, forests, and wetlands (Guo et al., 2016; Mganga et al., 2016). Soil microbial communities participate in specific biochemical reactions that play an important role in the regulation and cycling of nutrients; as such, they are part of the local ecosystem and have a large impact on soil quality and plant biomass (Hernandez et al., 2016). Jangid et al. (2011) found that transforming a wetland into an arable land resulted in significant changes in the bacterial abundance and species, and that such a change of land use was the main factor determining the microbial community composition. Krashevska et al. (2015) compared the short-term impact of changed land use, from a natural rainforest to a commercial rubber plantation, and reported that the bacterial abundance in the soil significantly decreased as a result. Mendes et al. (2015) revealed that the content of bacteria belonging to the genera of Acidophilus and Chlamydia was higher in forest soil, while the content of Actinomycetes members was higher in the logging area of a forest land and the content of nitrifying, thermophilic 
bacteria were higher in arable land. Wood et al. (2017) showed that when oil palms were planted where tropical forest had been removed, the bacterial diversity increased; regeneration of the forest eventually resulted in only slight differences in bacterial diversity and community composition compared to the original forest land. We envisage that a comprehensive assessment of land use patterns, soil characteristics, and the interaction between the soil bacterial community structure and its diversity will improve the understanding and management of terrestrial ecosystems.

Jiangsu Province is the dominant commodity grain producing area in China, due to its rich soil that has allowed for a long history of farming. The local soil physicochemical properties and fertility are highly important to establish sustainable agricultural practices (Wu et al., 2017). Secured grain production of local regions directly affects the grain security of the whole province and even of the whole country. Since the 1980s, this region has secured arable land by means of land reclamation to solve the food problems associated with an increasing population. However, over time the crop yield is not stable and when the local production is no longer economically viable, the land is abandoned and new land is reclaimed. This reclamation of land includes primitive wetlands, which are changed into arable land, at the cost of the natural wetland vegetation. Subsequent abandonment of the used arable land exposes the soil, causing serious erosion, and it is difficult to restore the original plant community ( $\mathrm{Li}$ et al., 2008). In the beginning of the $20^{\text {st }}$ century, the Yancheng country, which lies within the Jiangsu Province, realized the consequences of this practice were serious and caused severe environmental problems, so they transformed a number of wetlands and abandoned lands into forest lands, in an attempt to protect the local fragile ecosystem and promote sustainable and stable economic development (Frederic et al., 2014; Xu et al., 2014).

At present, there are few studies that have investigated the effects of land use changes on the soil microorganisms in the Yancheng county, in particular following decades of use. Here, we tried to fill this knowledge gap. We hypothesized that the conversion of wetland to arable land, or the reclaimed and abandoned arable land to forests, was not only accompanied with diverse and different vegetation, but also with long-term changes in the soil microbial communities, and these in turn would affect the soil physiochemical or biological factors. We expected that the structure and composition of mature microbial communities would depend upon the specific land use and would be associated with the aboveground vegetation. To investigate this, three different land use patterns in the Yancheng county were compared, namely primitive wetland, wetland that had been conversed to arable land decades ago and has since been used mainly for wheat production, and reclaimed land planted with a 30-year old pine forest. The physicochemical properties of the soil and the structure of the soil bacterial community were compared for these plots to characterize the changes induced by long-term land use. This information can provide a scientific basis for the maintenance and cultivation of soil fertility and the protection of soil microbial diversity, as well as for the ecological reconstruction and rational utilization of land resources in this area.

\section{Materials and methods}

\section{Description of the research site}

The research site was located in the Yancheng National Natural Reserve of Jiangsu Province, China $\left(32^{\circ} 48^{\prime} 47^{\prime \prime}-34^{\circ} 29^{\prime} 28^{\prime \prime} \mathrm{N}, 119^{\circ} 53^{\prime} 45^{\prime \prime}-121^{\circ} 18^{\prime} 12^{\prime \prime} \mathrm{E}\right)$. The area is located 
in the transition area between the warm temperate zone and the northern subtropical zone. The local climate is mainly affected by the ocean and continental climate (Wang et al., 2020). The average annual temperature is $13.7-14.6{ }^{\circ} \mathrm{C}$, the average annual rainfall is $1000 \mathrm{~mm}$, with rainfall concentrated in summer combined with dry winters, and a seasonality with mild temperatures in winter and summer (Wang et al., 2020). Three plots with different land-use patterns were selected for this study, representing primitive wetland, arable land that was reclaimed from wetland some 50 years ago, and forest land. The primitive wetland has a total area of approximately $1000 \mathrm{hm}^{2}$ with the most common vegetation existing of Echinopsis, Myriophyllum sp. (water milfoil), Psyllium chinense, Gymnema sylvestris (a climbing perennial), Carex sibiricum (a grass species), Artemisia halodendron and Artemisia serrata. The arable land of approximately $500 \mathrm{hm}^{2}$ in total is mostly used for wheat production and the soil is yearly ploughed mechanically. In spring, $30 \mathrm{~kg} / \mathrm{mu}$ of compound fertilizer $\left(\mathrm{N}+\mathrm{P}_{2} \mathrm{O}_{5}+\mathrm{K}_{2} \mathrm{O} \geqq 45 \%\right)$ is typically applied and in the middle of June, $15 \mathrm{~kg} / \mathrm{mu}$ of top dressing is applied. The forest land has an area of approximately $500 \mathrm{hm}^{2}$ and was planted with a monoculture of Pinus sylvestris 30 years ago. Prior to that it had been in use as arable land for an unknown period of time.

\section{Sample collection}

In June 2019, three standard $50 \mathrm{~m} \times 50 \mathrm{~m}$ plots were selected from the three different lands and soil samples of $0-20 \mathrm{~cm}$ depth were obtained by the five-point mixed sampling method. After removing any stones and plant roots, the five samples from each plot were evenly mixed and then passed through a $2 \mathrm{~mm}$ sieve. Aliquots of the samples were stored at $-80{ }^{\circ} \mathrm{C}$ in $15-\mathrm{mL}$ centrifuge tubes in liquid nitrogen for DNA extraction and microbiological analysis. The remaining soil was divided into two parts: one part was stored at $4{ }^{\circ} \mathrm{C}$ and the other was dried naturally to determine the soil physicochemical properties.

\section{Determination of physicochemical properties of soil samples}

The soil moisture content (MC) was determined for fresh samples. These were weighed in an aluminum box using a scale with an accuracy of $0.01 \mathrm{~g}$, a cover was placed obliquely, and the soil was dried for $8 \mathrm{~h}$ at a controlled temperature of $10{ }^{\circ} \mathrm{C} \pm 2{ }^{\circ} \mathrm{C}$. When the weight was constant the dry weight was determined and the soil $\mathrm{MC}$ was calculated. The $\mathrm{pH}$ was measured using a $\mathrm{pH}$ meter after adding water at a soil-water ratio of 2.5:1 (g:g). The organic matter in the soil was proxied by total organic carbon (TOC) content which was determined using a Vario-TOC instrument (Elementar, Germany). For determination of total nitrogen (TN) $2 \mathrm{~g}$ of accelerating agent mixed with zinc sulfate and copper sulfate and $5 \mathrm{~mL}$ of concentrated $\mathrm{H}_{2} \mathrm{SO}_{4}$ were added to $0.25 \mathrm{~g}$ soil and this mixture was passed through a $0.149 \mathrm{~mm}$ sieve. After digestion, the sample was filtered at constant volume and then measured with a continuous flow analyzer. To determine nitrogen present in the form of nitrate and ammonium, $10 \mathrm{~mL}$ of $1 \mathrm{~mol} / \mathrm{L} \mathrm{KCl}$ was added to $6 \mathrm{~g}$ of air-dried soil. After shaking for $1 \mathrm{~h}$, the mixture was filtered and the sample was measured using a continuous flow analyzer. Total P (TP) was determined by the Molybdenum colorimetry method with sulfuric acid and perchlorate acid extraction. Soil-available $\mathrm{P}$ was determined by prior extraction with $0.5 \mathrm{~mol} / \mathrm{L} \mathrm{NaHCO}_{3}$. Total $\mathrm{K}$ and available $\mathrm{K}$ were determined by atomic absorption spectrometry. 


\section{DNA extraction and high throughput sequencing}

Genomic DNA was extracted from $0.5 \mathrm{~g}$ of fresh soil samples $(\mathrm{n}=18)$ using the Power Soil DNA extraction kit (MoBio Inc., USA) according to the manufacturer's instructions. The extracted DNA was checked by $1 \%$ agarose gel electrophoresis. The internal V3 region of the bacterial $16 \mathrm{~S}$ rRNA gene was amplified by PCR using the universal BAC primer set 338F (5'-ACTCCTACGGGAGGCAGCA-3') and 806R (5'-GGACTACHVGGGTWTCTAAT-3') (Huse et al., 2008) by a standard protocol using a GeneAmp 9700 amplifier. The amplicons were checked by $2 \%$ agarose gel electrophoresis and then recovered from the gel using the AxyPrep DNA gel extraction kit (Axygen Biosciences, USA). The purified amplicons were quantified by QuantiFluor $^{\mathrm{TM}}$ (Promega) and their concentrations were adjusted as needed for sequencing. Sequencing was performed by Majorbio Technologies Co., Ltd. (Shanghai, China) on an Illumina MiSeq platform.

\section{Sequence analysis of the $16 \mathrm{~S}$ rRNA gene}

The original fastq sequence file was quality filtered by Trimmatotic (www.kbase.us) and then merged by FLASH (Fast Length Adjustment of Short reads). Sequences were discarded when their length was shorter than $50 \mathrm{bp}$ and the average quality score was below 20, or when more than two nucleotide mismatches were present or base deletions were found; those sequences that passed were merged when they overlapped for more than $10 \mathrm{bp}$.

Operational taxonomic units (OTUs) were defined using UPARSE (version 7.1, http://drive5.com/uparse/) at a 97\% similarity cutoff and chimeric sequences were identified with UCHIME and removed. The RDP classification algorithm (http://rdp.cme.msu.edu/) was used to classify the obtained 16S rRNA fragment sequences based on the SILVA (SSU123) database.

\section{Data analysis}

Alpha diversity analysis was performed using parameters for community richness (Chao and ACE indices) and diversity (Simpson and Shannon indices), as calculated by the Mothur software. The $\mathrm{R}$ software package was used to visually analyze the beta diversity and calculate the OTU level based on redundancy analysis (RDA). Student's $t$-test was used to analyze the differences of detected bacterial phyla in the different land use types.

Beta analysis was compared by calculation of Bray-Curtis distances, to quantify the compositional dissimilarity between two different sites. The results were summarized in a Principle coordinates analysis (PCoA). One-way analysis of variance (ANOVA) was used to analyze the effect of different land use types on soil properties and microbial diversity. Duncan's test was used to identify significant differences for each index among different land use patterns $(\alpha=0.05)$. Distance-based redundancy analysis (db-RDA) was performed by $\mathrm{R}$ software. A result of $P<0.05$ between groups was considered to be statistically significant. The results of all samples are presented as the mean \pm standard deviation. The Student's $t$-test, One-way ANOVA, and Duncan's test were performed by SPSS 20.0. 


\section{Results}

\section{Changes of soil physicochemical properties under different land use patterns}

The physicochemical properties of the soil collected from plots with three different land use patterns are shown in Table 1. The $\mathrm{pH}$ was slightly acidic for all three soil samples, although soil from forest land was significantly $(P<0.05)$ less acidic than the other two land types. As expected, the soil moisture content differed significantly between the three different land use types, with a three-times higher water content in wetland soil compared to arable land, and forest soil containing twice as much water compared to arable soil. The organic carbon content also differed significantly $(P<0.05)$, with arable land producing the lowest values and wetland soil containing 3.6 times more organic carbon; forest land contained 2.8 times more organic carbon than arable land. The total nitrogen content was highest for wetland soil, followed by arable soil while forest soil had the lowest total nitrogen content. A different trend was observed for total phosphorus, which was lowest for arable soil and highest for soil sampled from wetland. There were no significant differences in the contents of available $\mathrm{P}$ between the three soil types $(P>0.05)$.

Table 1. Physio-chemical properties of the three different land use soil types

\begin{tabular}{c|c|c|c|c|c|c}
\hline Type & $\mathbf{p H}$ & $\begin{array}{c}\text { Moisture content } \\
(\mathbf{\%})\end{array}$ & $\begin{array}{c}\text { Soil Organic Carbon } \\
(\mathbf{g} / \mathbf{k g})\end{array}$ & $\begin{array}{c}\text { Total Nitrogen } \\
(\mathbf{g} / \mathbf{k g})\end{array}$ & $\begin{array}{c}\text { Total } \\
\text { Phosphorus } \\
(\mathbf{g} / \mathbf{k g})\end{array}$ & $\begin{array}{c}\text { Available } \\
\text { phosphorus } \\
(\mathbf{m g} / \mathbf{k g})\end{array}$ \\
\hline Wetland & $5.23 \pm 0.12^{\mathrm{b}}$ & $63.23 \pm 0.27^{\mathrm{a}}$ & $43.23 \pm 0.51^{\mathrm{a}}$ & $4.29 \pm 2.41^{\mathrm{a}}$ & $2.42 \pm 0.59^{\mathrm{a}}$ & $28.41 \pm 1.74^{\mathrm{a}}$ \\
Forest land & $6.76 \pm 0.10^{\mathrm{a}}$ & $36.43 \pm 0.52^{\mathrm{b}}$ & $33.51 \pm 0.51^{\mathrm{b}}$ & $2.03 \pm 2.12 \mathrm{c}$ & $1.23 \pm 0.31^{\mathrm{b}}$ & $20.21 \pm 2.15^{\mathrm{a}}$ \\
Arable land & $5.62 \pm 0.11^{\mathrm{b}}$ & $12.42 \pm 0.82^{\mathrm{c}}$ & $12.42 \pm 0.08^{\mathrm{c}}$ & $3.14 \pm 1.05^{\mathrm{b}}$ & $0.71 \pm 0.02^{\mathrm{b}}$ & $23.33 \pm 1.10^{\mathrm{a}}$ \\
\hline
\end{tabular}

Statistical significance is indicated by superscripts per column

\section{Changes in soil microbial alpha and beta diversity under different land use patterns}

Based on sequences obtained from amplified 16S rRNA V3 fragments, the alpha diversity indices of the captured soil bacterial communities were calculated and these significantly differed between forest land and arable land (Table 2). The highest number of OTUs was obtained from forest land, while arable land produced lower numbers. There was no significant difference in Shannon and Simpson indices for the three soil types $(P>0.05)$. However, the Ace index was significantly $(P<0.05)$ lower and the Chao1 index significantly higher for forest soil than for the other two soil types. In combination the results indicate that there were no extreme differences in bacterial diversity among the three land use patterns, but the bacterial abundance was highest in the arable soil and lowest in the forest soil.

Table 2. Diversity indices of the soil bacterial communities

\begin{tabular}{c|c|c|c|c|c}
\hline Types & OTUs & Shannon & Simpson & Ace & Chao1 \\
\hline Wetland & $1927.00 \pm 80.29^{\mathrm{ab}}$ & $6.11 \pm 0.16^{\mathrm{a}}$ & $0.005 \pm 0.001^{\mathrm{a}}$ & $2365.14 \pm 189.09^{\mathrm{a}}$ & $2351.63 \pm 169.89^{\mathrm{ab}}$ \\
Forest land & $1954.00 \pm 365.42^{\mathrm{a}}$ & $6.26 \pm 0.05^{\mathrm{a}}$ & $0.006 \pm 0.001^{\mathrm{a}}$ & $1899.19 \pm 155.58^{\mathrm{b}}$ & $1903.56 \pm 170.98^{\mathrm{b}}$ \\
Arable land & $1919.00 \pm 204.18^{\mathrm{b}}$ & $6.13 \pm 0.72^{\mathrm{a}}$ & $0.021 \pm 0.002^{\mathrm{a}}$ & $2355.01 \pm 172.76^{\mathrm{a}}$ & $2371.02 \pm 183.54^{\mathrm{a}}$ \\
\hline
\end{tabular}


The beta diversity of the bacterial communities was compared by principal coordinates analysis (PCoA) based on Bray-Curtis distances. The first component represented over $34 \%$ of the data and the second component nearly $22 \%$ of the data. The differences in bacterial community structure among the different soil types were significant (PERMANOVA: $\mathrm{r}=0.48, P<0.01$, while the differences within individual samples of the same soil type were insignificant (Fig. 1). Two of the three forest samples were very similar in community structure but the third sample was quite different. Similarly, one of the three arable samples was quite distinct (in the second PC dimension only). Moreover, it can be seen that the bacterial community structures of wetland and arable soil were more similar to each other and notably different to that of forest soil. This indicates that long-term land use types changes can lead to different bacterial community structures, but the results depend on the type of land use. Apparently, the strongest effect resulted from forestry, whereas wheat production had less of an effect on the bacterial community structure of the soil.

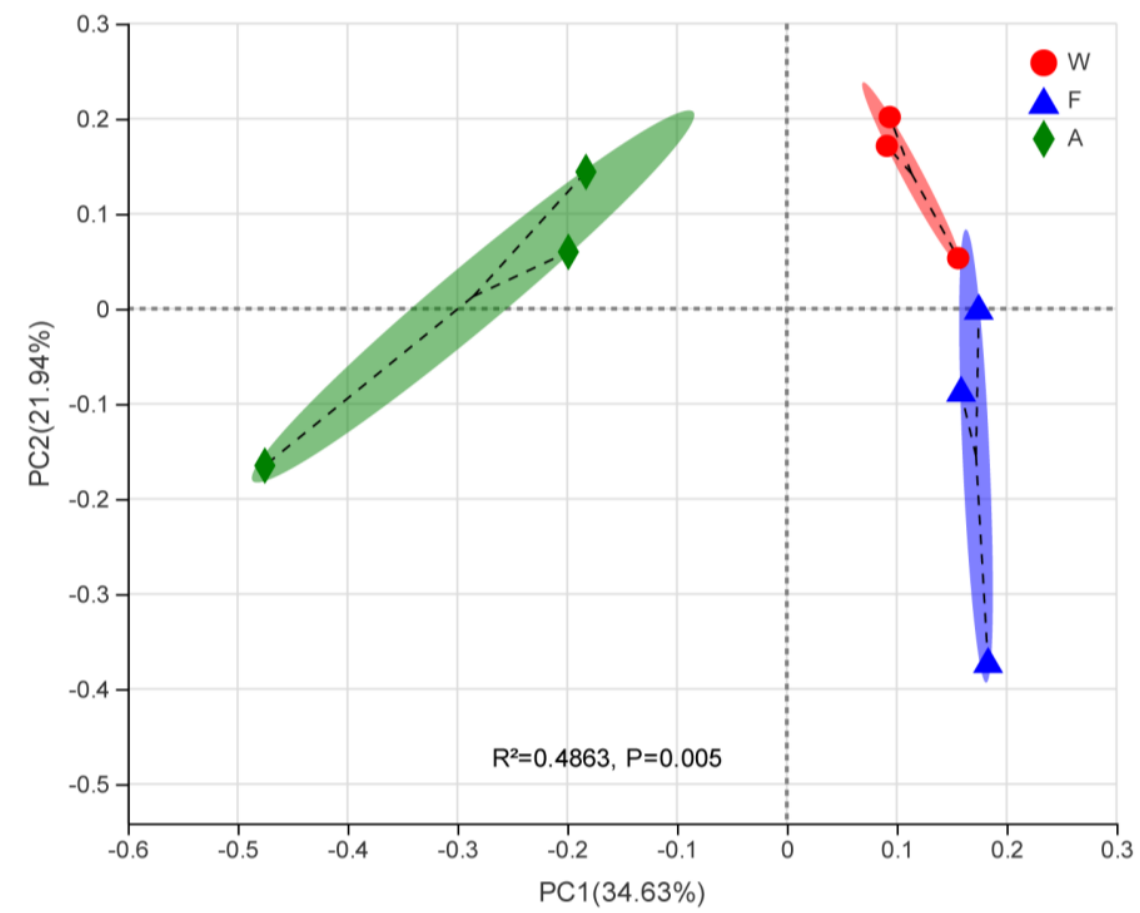

Figure 1. PCOA of the beta diversity within and between bacterial communities of different land use soil types. Wetland soil samples are shown in red (w), forest soil samples in blue $(F)$, and arable soil samples in green $(A)$

\section{Analysis of soil bacterial community structure under different land use types}

All obtained sequence reads that could be attributed to an OTU in combination represented 58 bacterial phyla; sequences to which an OTU could not be attributed at the phylum level were uniformly grouped as "others". Of the OTUs obtained from all three soil types combined, Acidobacteria were the most abundant, followed by, Proteobacteria, Actinobacteria, and, as the fourth most abundant phylum, Chloroflexi (Fig. 2A). The relative abundances of these highly abundant phyla varied between the soil types. The soil from primitive wetland was relatively rich in Acidobacteria, which 
represented over $41 \%$ of all obtained sequence reads (Fig. 2B), followed by Proteobacteria and Actinobacteria. Soil from land used for forestry over the past 30 years contained more Actinobacteria and fewer Actinobacteria compared to the wetland soil (Fig. 2C). Soil transformed into arable land was relatively rich in Proteobacteria but contained few Actinobacteria. It also contained a strikingly large fraction of Firmicutes (Fig. 2D).

Community analysis pieplot on Phylum level :All

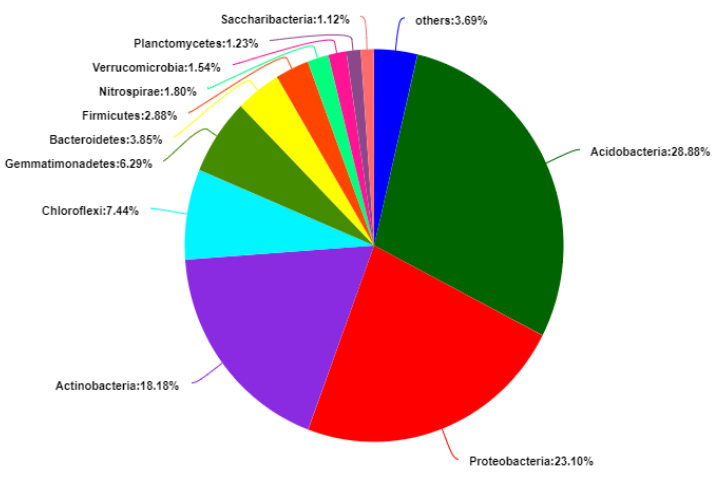

Community analysis pieplot on Phylum level :Forest land

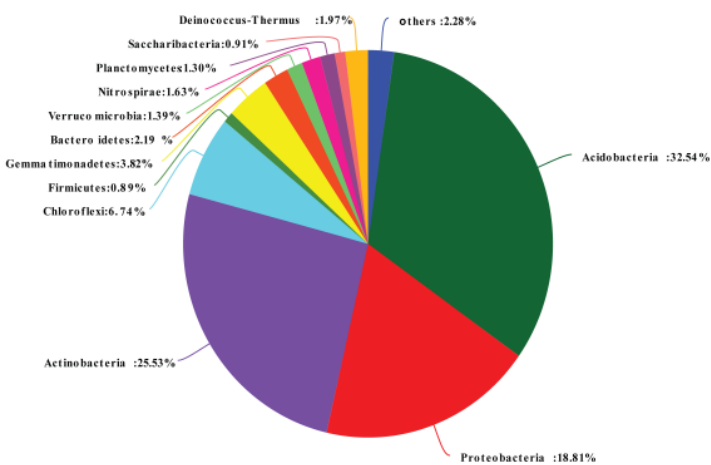

Community analysis pieplot on Phylum level :Wetland

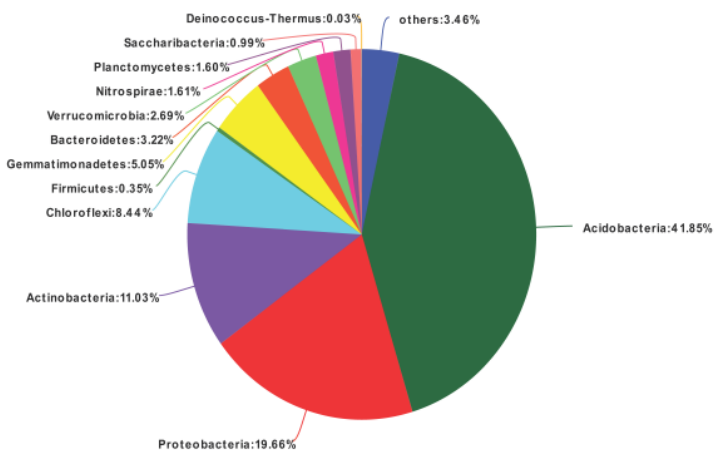

Community analysis pieplot on Phylum level :Arable land

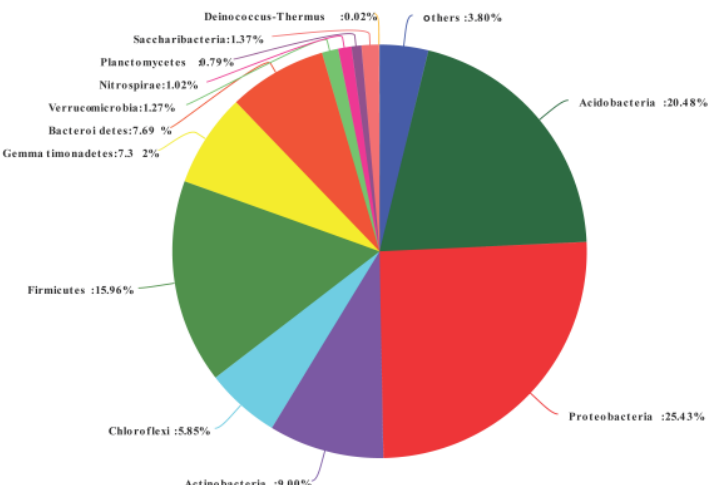

Figure 2. Bacterial community composition at the level of phyla, for all obtained sequences (top) and for the three different land use soil types

Differences in relative abundance of bacterial phyla were analyzed for the different soil types using two-sample $t$-tests. Three phyla were significantly different $(P<0.05)$ between the wetland and forest soil (Fig. 3A), namely Actinobacteria $(\mathrm{P}<0.01)$, Verrucomicrobia, and Latescibacteria (both $\mathrm{P}<0.05$ ). The latter phylum was found at low abundance but significantly higher in wetland than in forest soil. There were six phyla with significant differences $(\mathrm{P}<0.05$ for all $)$ in relative abundance between the wetland and arable soil (Fig. 3B): Acidobacteria, Bacteroidetes, Plantomycetes, Latescibacteria, Plantomycetes, and WWE3. Further, there were three phyla with significant differences $(P<0.01)$ between the forest and arable soil (Fig. 3C), namely Actinobacteria, Bacteroidetes, and low-abundant WWE3 members, plus Plantomycetes that differed at a level of $P<0.05$ (Fig. 3C). 
Student's t-test bar plot on Phylum level
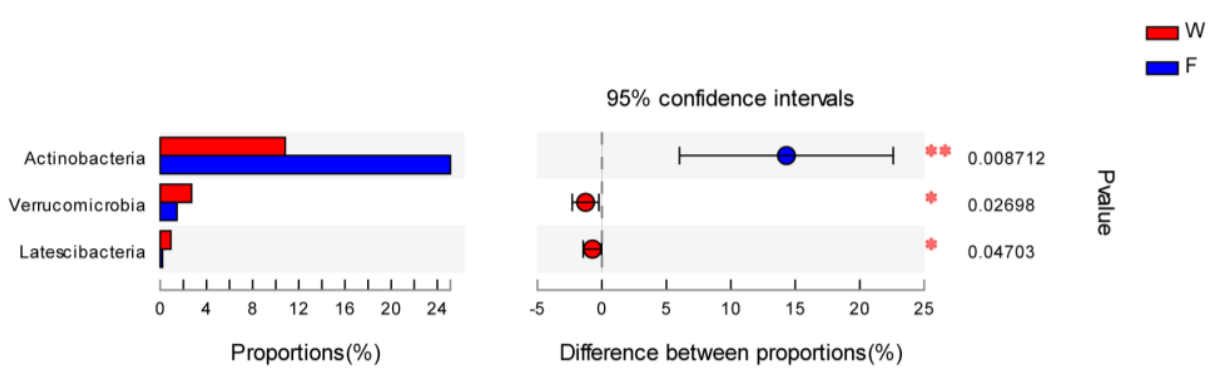

Student's t-test bar plot on Phylum level
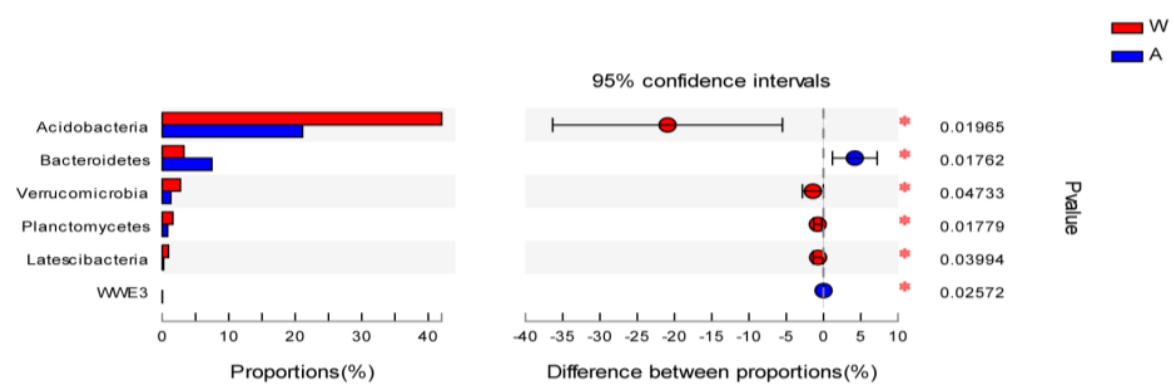

Student's t-test bar plot on Phylum level
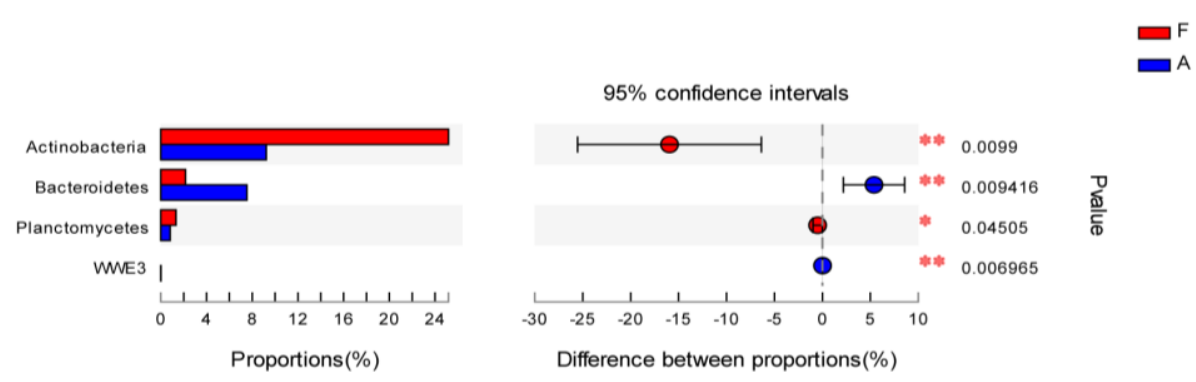

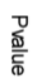

Figure 3. Student t-test evaluating pairwise differences in bacterial abundance at the phylum level in the soil types, with W: wetland; F: forest land; A: arable land. Significance is represented with * at $P<0.05$ level and with $* *$ at $P<0.01$

\section{Redundancy analysis of the soil bacterial community and physicochemical properties of the different land use soil types}

Distance-based redundancy analysis (db-RDA) was conducted to determine relationships between the soil physicochemical properties and the bacterial community compositions at the phylum level (Fig. 4). The first axis explained $48.89 \%$ of all information and the second axis explained $7.37 \%$; thus, in combination these capture $88.68 \%$ of the variability. Associations between the physico-chemical parameters deviating from the origin are indicated by arrows. Longer arrows such as for $\mathrm{pH}, \mathrm{MC}$, and to a lesser extent TP indicate that these parameters had a stronger impact on the bacterial community composition, while the shorter arrows of SOC, AP and TN indicate that these parameters had less impact. AP and TP values are associated (which is to be expected) and negatively correlate with the other determined parameters. The bacterial community composition of wetland soil correlated with lower $\mathrm{pH}$ and the three wetland samples correlated with MC, as could be expected. Two of the three forest soil samples also correlated with MC and to a lesser extent to AP. 


\section{db-RDA on Genus level}

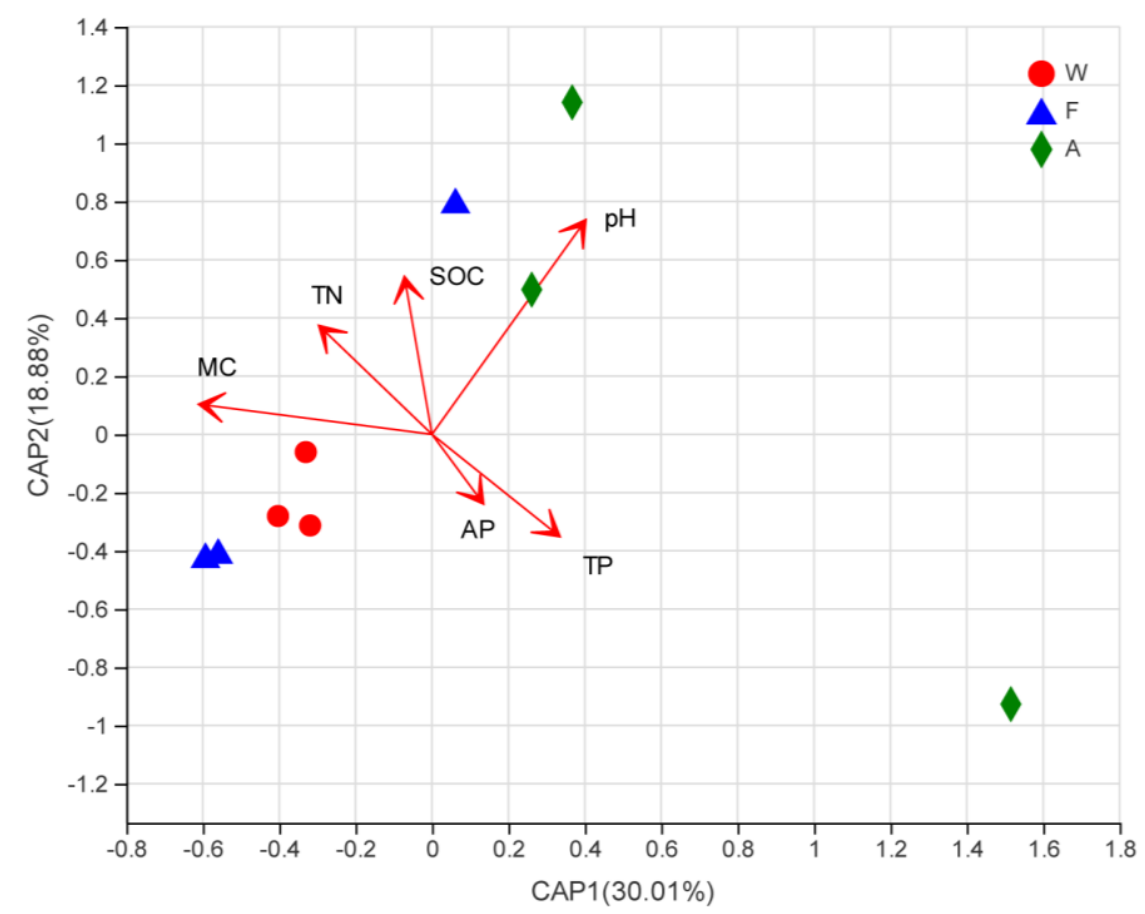

Figure 4. Distance-based redundancy analysis of the soil bacterial community structure at phylum level and the determined soil physicochemical properties. W: wetland; F: forest soil; A: arable land soil; SOC: soil organic carbon; TN: total nitrogen; MC: moisture content; TP: total phosphor; AP: available phosphor, $\mathrm{pH}$, acidity (the arrow indicates high $\mathrm{pH}$ )

\section{Discussion}

\section{Effects of land use types on the composition and diversity of the soil microbial community}

Changes in the soil microbial community diversity can reflect the quality and health a soil ecosystem (Wang et al., 2013). The interference of human activities on natural ecosystems is the most important direct driving force that influences and changes a local ecosystem, in which the microbial soil community has important functions. Studying the changes of bacterial community structures and local diversities can reveal differences of the Yancheng wetlands under different land uses (Liu et al., 2006a,b). Here we confirm that different land use significantly changed the ACE and Chao1 indices of the detected soil bacterial communities, with significant changes in relative abundance of members of the bacterial community. Soil collected from arable land and forest land resulted in higher bacterial community abundances compared to relatively pristine wetland. Decades ago these arable and forest lands had been wetlands. The change in land use did not alter the three dominant phyla detected in the soil, which were (in order of decreasing abundance) Acidobacteria, Proteobacteria, and Actinobacteria. These three phyla accounted for more than $80 \%$ of the total bacterial community in the samples, which is consistent with the results of previous studies on the structure of soil microbial communities (Zhang et al., 2016; Zeng et al., 2017). However, the relative abundance of the dominant phyla changed significantly. In arable land, Firmicutes were much more abundant, overtaking acidobacteria as the third-most 
abundant phylum, while this phylum was relatively moderate in numbers detected for wetland or forest soil. Compared with the primitive wetland, in forest soil the relative abundance of Actinobacteria was higher; Proteobacteria were more abundant in arable land than in the other two soil types, and Acidobacteria were particularly abundant in wetland.

Previous studies have shown that in particular Proteobacteria and Actinomycetes (a family within the Actinobacteria phylum) are involved in the decomposition of organic matter (Li et al., 2016). Furthermore, Proteobacteria and Acidobacteria are often used as indicators of the soil nutritional status due to their lifestyles (Hartman et al., 2008). For instance, previous studies have reported that the relative abundance of Proteobacteria is positively correlated with soil carbon content, and that their abundance increases with increasing organic matter, especially in nutrient-rich soil (McCaig et al., 1999; Bardhan et al., 2012). Members of Proteobacteria are considered to be mainly responsible for utilization of higher carbon sources and may represent the most common bacterial phylum in the world. Acidobacteria contain many acidophilic species that are widely distributed in different soil environments and their relative abundance can relate to the acidity of the soil (Wei et al., 2016; Dang et al., 2017). Indeed, the lowest pH of the soils investigated in this study was recorded for wetland soil, which was rich in Acidobacteria (Table 1, Figure 2, Figure 4). Acidobacteria also negatively correlate to soil nutrition as they are generally more abundant in nutrient-poor soils. This fits with the observed higher abundance in the forest and wetland soil compared to the nutrient-rich arable soil. Actinomycetes are spore forming bacteria that dominate in poor soil conditions and they can decompose more refractory organic carbon by extending their hyphae into plant tissues (Xiao et al., 2014; Yu et al., 2016). In this study, Actinobacteria were the third-dominant group behind Acidobacteria and Proteobacteria for forest and wetland soil (they were fourth for nutrient-rich arable soil). Generally speaking, Proteobacteria are more abundant in soil with a less acidic $\mathrm{pH}$ and in near-neutral soil they can outcompete other bacteria by their efficient use of more complex organic carbon sources, while organic carbon with low bioavailability in acidic soil is beneficial to Acidobacteria.

The observed differences in abundance of bacterial phyla is likely caused by the change of soil structure and nutrient supply related to decade-long human agricultural and forestry practices (Wang et al., 2013). Ploughing practiced on the arable lands causes frequent disturbance of the soil (Liu et al., 2009), making the distribution of soil nutrients more uniform and adding aeration. This likely explains the higher diversity of the microbial community compared to the primitive wetland. It is also possible that the higher moisture content of the wetland results in lower oxygen contents, which may also reduce soil bacterial community diversity. Compared with the primitive wetland, the soil from arable and forest land produced significantly higher abundances of soil bacterial communities.

\section{Correlations between soil physicochemical properties and the composition of the soil microbial community}

We found that total $\mathrm{P}$ and available $\mathrm{P}$ were important factors correlating to the bacterial community structure (Fig. 4). These results are similar to those of Wang et al. (2013). Land use types determine the vegetation type and soil management practices, subsequently affecting soil nutrients (Zhang et al., 2016; Li et al., 2016). Changes in soil nutrients likely affect the microbial community structure, and the addition of different 
nutrient amounts will increase the microbial community structure and its functional diversity (Hartman et al., 2008). Bacteria are the most diverse microbial group in soil and they are extremely sensitive to environmental variation (McCaig et al., 1999). Like all other living organisms bacterial need phosphor, the bacterial cell wall contains a large amount of phosphonic acid, especially in Gram-positive bacteria, where it can account for about $50 \%$ of the dry cell weight (Bardhan et al., 2012). In this study, the content of total $\mathrm{P}$ but not available $\mathrm{P}$ was significantly lower in the cultivated and forest soil than in the wetland soil (Table 1), which may be because the forest canopy intercepts an in water, thereby decreasing surface runoff, which enables retention of the soil surface organic matter and mineral nutrition. This could allow the soil nutrient content in the forest land to be significantly higher than that in cultivated land; however, subsequent artificial fertilization of the cultivated land could compensate the nutrition of the soil (Dang et al., 2017). However, the wetland has no external nutrient supplementation, and vegetation growth utilizes the absorbed $\mathrm{P}$ in the soil, resulting in low total P and available P contents. Soil P is not only an energy source for the soil bacterial community, but also an important resource for plant growth (Dang et al., 2017). The special black soil habitat of the Yancheng wetland increases the amount of $\mathrm{P}$ adsorption (Wei et al., 2016), but the main source of soil $\mathrm{P}$ is the soil parent material, which is a single source. In addition, at the peak of vegetation growth in the black soil area of the Yancheng wetland, the soil $\mathrm{P}$ under different land use patterns may be redistributed within the plant-soil-microbial system, which makes the $\mathrm{P}$ content an important factor affecting the soil bacterial community variance (Xiao et al., 2014).

Different soil fertility and environmental conditions will alter the soil microbial population to varying degrees (Rani et al., 2009; Niu et al., 2011; Dhal et al., 2011). Studies have shown that the contents of soil organic carbon, total $\mathrm{N}$ and other nutrients depend on different land uses, and that the relative richness of dominant bacteria at the phylum and class level are also different. It is likely that changes in the soil nutrient content can lead to changes in soil bacterial composition and community structure (Wang et al., 2013; Xu et al., 2014). In primitive wetlands, soil $\mathrm{pH}$, together with the water content and the degree of aeration, are important parameters affecting the metabolism and growth of plants and microorganisms alike; thus, changes in these parameters will inevitably lead to changes in the microbial community structure. Previously it has been shown (Dang et al., 2017) that soil pH exhibits an excellent correlation with microbial community diversity, because different bacteria have different environmental $\mathrm{pH}$ requirements, with even slight changes having a significant impact on the microbial community structure (Niu et al., 2017). In addition, soil nutrients are an important factor affecting the soil microbial community structure (Wei et al., 2016). Under eutrophic conditions, the limiting effect of $\mathrm{P}$ on the original microbial community is greatly reduced and the metabolic activities of the microorganisms change, which may change their species composition (Dang et al., 2017). Reclamation of primitive wetlands into arable land can change the $\mathrm{pH}$, water content, and nutrients in the soil, thus affecting the microbial community structure.

\section{Conclusions}

After long-term changes in land use patterns of what was originally wetland, changes of the soil physicochemical properties mainly manifested as a decreased soil moisture content and an increase in $\mathrm{pH}$, which was observed for both arable land and forest soil, 
together with an increased total and available $\mathrm{P}$, indicating that the change in soil physicochemical properties has an impact on the structure of the soil microbial community.

The abundance of Proteobacteria, which is related to carbon utilization, was significantly higher in the arable land soil than that in the forest and wetland soils, while Acidobacteria, which is adapted to more acidic conditions, was significantly higher in the forest land and in particular in wetland soils. In the future we are planning to a comprehensive study to determine the interactions between soil microbial diversity and communities and the different land use soil types in combination with different aboveground plant compositions in the Yancheng wetland to further investigate the local ecosystems and formulate recommendations for the conservation of the wetlands.

Acknowledgements. This research were supported by Open Foundation of Shanghai Key Laboratory of Plant Functional Genomics and Resources (PFGR201803); Jiangsu Agricultural Industry Technology System (JATS-2020-3400); The Natural Science Foundation of the Jiangsu Higher Education Institutions of China (18KJB220011); Basic Research on Agricultural Application in Suzhou (SNG2018052); Suzhou Polytechnic Institute of Agriculture Young Teacher Research Capacity Improvement Program (19QN1010); Suzhou Polytechnic Institute of Agriculture Technology Cultivation Project(PY2003).

\section{REFERENCES}

[1] Bardhan, S., Jose, S., Jenkins, M. A., Webster, C. R., Udawatta, R. P., Stehn, S. E. (2012): Microbial community diversity and composition across a gradient of soil acidity in spruce-fir forests of the southern Appalachian Mountains. - Applied Soil Ecology 61: 6068.

[2] Dang, P., Yu, X., Le, H., Liu, J., Zhao, Z. (2017): Effects of stand age and soil properties on soil bacterial and fungal community composition in Chinese pine plantations on the loess plateau. - PLoS ONE 12(10): e0186501.

[3] Dhal, P. K., Islam, E., Kazy, S. K., Sar, P. (2011): Culture-independent molecular analysis of bacterial diversity in uranium-ore/-mine waste-contaminated and noncontaminated sites from uranium mines. - Biotech. 1(4): 261-272.

[4] Guo, X. P., Chen, H. Y. H., Meng, M. J., Biswas, S. R., Ye, L. X., Zhang, J. C. (2016): Effects of land use change on the composition of soil microbial communities in a managed subtropical forest. - Forest Ecol Manag. 373: 93-99.

[5] Hartman, W. H., Richardson, C., Vilgalys, R., Bruland, G. L. (2008): Environmental and anthropogenic controls over bacterial communities in wetland soils. - PNAS 105(46): $17842-17847$.

[6] HernándeZ, Á., Arellano, E. C., Morales-Moraga, D., Miranda, M. D. (2016): Understanding the effect of three decades of land use change on soil quality and biomass productivity in a Mediterranean landscape in Chile. - Catena 140: 195.

[7] Jangid, K., Williams, M. A., Franzluebbers, A. J., Schmidt, T. M., Coleman, D. C., Whitman, W. B. (2011): Land-use history has a stronger impact on soil microbial community composition than aboveground vegetation and soil properties. - Soil Biol. Biochem. 43(10): 2184-2193.

[8] Krashevska, V., Klarner, B., Widyastuti, R., Maraun, M., Scheu, S. (2015): Impact of tropical lowland rainforest conversion into rubber and oil palm plantations on soil microbial communities. - Biol Fert Soils 51(6): 685-697.

[9] Li, Y. J., Chen, L., Li, L. Y. (2008): Study on the development trend of land desertification in the western part of Heilongjiang Province. - Prot Forest Sci Technol. 5: 98-102. 
[10] Li, X., Sun, M., Zhang, H., Xu, N., Sun, G. (2016): Use of mulberry-soybean intercropping in salt-alkali soil impacts the diversity of the soil bacterial community. Microb Biotechnol. 9(3): 293-304.

[11] Liu, Y. Y., Yao, H. Y., Huang, C. Y. (2006): Influence of soil moisture regime on microbial community diversity and activity in a paddy soil. - Acta Pedologica Sinica 43(5): 828.

[12] Liu, Y. Y. (2009): Relationship between soil moisture regime and microbial biomass, activity, diversity in paddy soils. - Hangzhou: Zhejiang University 93.

[13] McCaig, A. E., Glover, L. A., Prosser, J. I. (1999): Molecular analysis of bacterial community structure and diversity in unimproved and improved upland grass pastures. Appl Environ Microbiol. 65(4): 1721-1730.

[14] Mendes, L. W., de Lima Brossi, M. J., Kuramae, E. E., Tsai, S. M. (2015): Land-use system shapes soil bacterial communities in Southeastern Amazon region. - Appl Soil Ecol. 95: 151-160.

[15] Mganga, K., Razavi, B., Kuzyakov, Y. (2016): Land use affects soil biochemical properties in Mt. Kilimanjaro region. - Catena 141: 22-29.

[16] Niu, J., Zhou, X., Jiang, N., Wang, Y. (2011): Characteristics of soil microbial communities under dry and wet condition in Zoigealpine wetland. - Acta Ecologica Sinica 31(2): 474-483.

[17] Rani, A., Sharma, A., Rajagopal, R., Adak, T., Bhatnagar, R. K. (2009): Bacterial diversity analysis of larvae and adult midgut microflora using culture-dependent and culture-independent methods in lab-reared and field-collected Anopheles stephensi - an Asian malarial vector. - BMC Microbiol. 9(1): 96-101.

[18] Sun, R., Sun, B. H., Gao, M. X., Yang, X. Y., Zhang, S. L. (2015): Changes of soil microbial characteristics under long-term different land use patterns on an anthropogenic loess soil. - J Plant Nutriti Fertilizers 21(3): 1-10.

[19] Wang, L. J., Li, G., Zhao, J. N., Xiu, W. M., Zhang, Q. Y. (2013): Effects of Transgenic Soybeans on the Microbial Functional Diversity in the Rhizosphere. - J Agro-Environ Sci. 32(2): 290-298.

[20] Wang, S., Liu, X. T., Mou, X. J., Zhao, Y. Q. (2020): Comparison of Carbon, Nitrogen, and Sulfur in Coastal Wetlands Dominated by Native and Invasive Plants in the Yancheng National Nature Reserve, China. - Chin Geograp Sci. 30(2): 202-216.

[21] Wei, F., Xin, W. D., Liang, M., Pei, Z. (2016): Influence of organic cultivation on soil microbial community in cornfield. - Journal of Shanghai Jiaotong University 05.

[22] Wood, S. A., Gilbert, J. A., Leff, J. W., Fierer, N., Angelo, H. D., Bateman, C., Gedallovich, S. M., Gillikin, G. M., Gradocille, M. R., Mansor, P., Massmann, A., Yang, N., Turner, B. L., Brearley, F. Q., McGuire, K. L. (2017): Consequences of tropical forest conversion to oil palm on soil bacterial community and network structure. - Soil Biol Biochem. 112: 258-268.

[23] Wu, S. Q., W, C. Z., Li, M. S. (2017): On Soil Functional Diversity of Native Coastal Wetland Under Simulated Nitrogen Deposition. - Soils 49(6): 1153-1158.

[24] Xiao, W. D. (2014): Transformation and Movement Characterization and Diagnostic Index of Chromium pollution in representative Chinese soils. - Hangzhou: Zhejiang University 9.

[25] Xu, X., Schimel, J. P., Thornton, P. E., Song, X., Yuan, F., Goswami, S. (2014): Substrate and environmental controls on microbial assimilation of soil organic carbon: a framework for earth system models. - Ecol Lett. 17(5): 547-555.

[26] Yu, J., Yu, Z. H., Iikenaga, M., Sakai, M., Liu, X. B., Wang, G. H. (2016): Effects of manure application on the diversity of corn root endophytic bacterial communities at seedling stage in eroded mollisols. - Chin J Appl Ecol. 27: 2663-2669.

[27] Zeng, Q., An, S., Liu, Y. (2017): Soil bacterial community response to vegetation succession after fencing in the grassland of China. - Sci Total Environ. 609: 2-10. 
[28] Zhang, Y., Dong, S., Gao, Q., Liu, S., Zhou, H., Ganjurjav, H. (2016): Climate change and human activities altered the diversity and composition of soil microbial community in alpine grasslands of the Qinghai-Tibetan plateau. - Sci Total Environ. 562: 353-363. 